\title{
Evaluation of Root Canal Obturation by Micro-computed Tomography for Endodontic Training in Dental Students
}

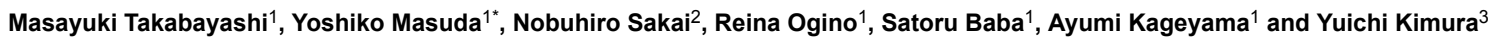 \\ ${ }^{1}$ Department of Conservative Dentistry, Division of Endodontology, Showa University School of Dentistry, 2-1-1 Kitasenzoku, Ohta-ku, Tokyo, Japan \\ ${ }^{2}$ Department of Pharmacology, Showa University School of Dentistry, 2-1-1 Kitasenzoku, Ohta-ku, Tokyo, Japan \\ ${ }^{3}$ Division of Endodontics, Department of Conservative Dentistry, Ohu University School of Dentistry, 31-1 Misumido, Tomita-machi, Koriyama, Fukushima, Japan
}

"Corresponding author: Yoshiko Masuda, DDS, PhD, Department of Conservative Dentistry, Division of Endodontology, Showa University School of Dentistry, 2-1-1 Kitasenzoku, Ohta-ku, Tokyo 145-8515, Japan, Tel: +81337871151; Fax: +81337871229; E-mail: yoshik@dent.showa-u.ac.jp

Rec date: Feb 15, 2016; Acc date: Mar 06, 2016; Pub date: Mar 13, 2016

Copyright: (c) 2016 Takabayashi M, et al. This is an open-access article distributed under the terms of the Creative Commons Attribution License, which permits unrestricted use, distribution, and reproduction in any medium, provided the original author and source are credited.

\begin{abstract}
Introduction: The purpose of this study was to evaluate the outcomes of root canal preparation and obturation by third year students who were performing root canal treatment for the first time, with micro-computed tomography (micro-CT) and compare the images taken at the first and second obturations for their training.

Methods: Single-rooted straight artificial right maxillary incisors for endodontic training were used for root canal preparation. The canals were obturated with gutta-percha and sealer. Six incisors judged to be well-obturated based on 2-D dental X-ray images were selected for micro-CT scanning. Based on the micro-CT images of the obturation performed for the first time, the areas for improvement were explained to each student individually. Then, root canal preparation and obturation were repeated using a new artificial tooth. The obturated artificial tooth was scanned by micro-CT. Digital three-dimensional (3-D) images were constructed. The volumes of the gaps and voids in the root canal and preparation size were calculated from the cementoenamel junction up to the apex after first and second root canal obturation.
\end{abstract}

Results: After first root canal obturation, mean value of the gaps and voids was reduced. Significant differences were observed between the first time and second time obturation group $(p=0.05)$. The mean value of the preparation size was slightly increased. No significant changes in the preparation size were observed.

Conclusions: These results suggested that micro-CT was an effective tool for evaluation of the outcome of endodontic training.

Keywords: Micro-computed tomography; Root canal obturation; Lateral condensation; Dental education

\section{Introduction}

Root canal treatment is not easy when performed for the first time in one's life, especially among dental school students. Each step performed within the root canal cannot be seen directly and is performed blindly, unlike other dental treatments. Dental school students learn the root canal anatomy, tools, materials, medicaments and the procedure of pulpectomy through lectures during the first 3 years of the course. In the third year, students have to practice root canal treatment in simple straight root canals and have to perform pulpectomy as the first step. After root canal preparation, canals are filled with gutta-percha and the sealer using a lateral condensation method.

Usually, the root canal treatment and obturation are evaluated by dental X-ray diagnostic imaging. Dental X-ray images show the obturation outcomes in one plane. Gaps and voids are often seen in the prepared root canal after obturation, but the X-ray diagnostic image does not show the existence of gaps and voids when they overlap with each other.
Micro-computed tomography (micro-CT) is a newer technology used to obtain a 3-D image of the root canals. It has emerged as a powerful tool for ex-vivo evaluation of root canal morphology because it is more accurate than anatomic sectioning [1-6]. Micro-CT enables analysis of canal volume, volume changes, cross-sectional shape, and gaps and voids in the filling materials $[7,8]$.

This study evaluates the outcomes of root canal preparation and obturation by third year students with micro-CT, compared to dental $\mathrm{X}$-ray images.

These 3-D images help to visualize and understand the outcomes of root canal preparation and obturation by students. We hypothesized that the results of gaps and voids and preparation size after second time obturation would be better than those after first time obturation.

\section{Materials and Methods}

A total of 106 dental school students in third year at Showa University attended the endodontic practice session. A single-rooted straight artificial right maxillary incisor for endodontic training (S-12-500; NISSIN, Kyoto, Japan) was used for root canal preparation.

The endodontic access cavities were prepared on the lingual tooth surface with round diamond burs (Morita Corp, Ltd, Tokyo, Japan) 
Citation: Takabayashi M, Masuda Y, Sakai N, Ogino R, Baba S, et al. (2016) Evaluation of Root Canal Obturation by Micro-computed Tomography for Endodontic Training in Dental Students. Dentistry 6: 368. doi:10.4172/2161-1122.1000368

Page 2 of 4

and penetration and unroofing by a round carbide bur. Canal orifices were located and identified with an ISO \#15 K-file (Micro-Mega SA, Besançon Cedex, France). Cervical dentine bulge was removed by a Gates-Glidden bur or Peeso reamer (Produits Dentaires, Vevey, Switzerland) which was placed just apical to the orifice and withdrawn in a distoocclusal direction band it is used to shape the axial wall in one plane from the orifice to the cavosurface margin. With coronal flaring, an ISO \#15 K-file was placed into the canal to ensure patency. Tooth length was determined as $24.5 \mathrm{~mm}$ from the incisal edge to the apical foramen. Working length was defined as $23.5 \mathrm{~mm}$. The root canal was enlarged until ISO \#35 K-file and, enlargement of the middle third of the root canal until ISO \#45 K-file was performed at a reduced length for $2 \mathrm{~mm}$ from working length. The canal was irrigated with distilled water to remove the debris in the root canal. The canal was dried with paper points. Finally, canals were obturated with guttapercha (GC Corp., Tokyo, Japan) and sealer (Canals-N; Showa Yakuhin Kako Co. Ltd, Tokyo, Japan).

The 2-D images of all artificial teeth were obtained by dental X-ray. Those judged to be well-obturated based on the 2-D dental X-ray image, were selected for micro-CT scanning. 6 well-obtured teeth were selected. The micro-CT imaging of the obturation performed first time was shown to the student individually and the areas for improvement were explained one by one. The root canal treatment and obturation were repeated using the same type of artificial tooth. All students performed root canal treatments twice with same type of artificial tooth. Finally, the obturated artificial teeth were scanned by micro-CT.

\section{Micro-CT imaging}

A micro-CT system (ScanXmate-L090H; Comscantecno Co. Ltd., Yokohama, Japan) was used to scan the artificial right maxillary incisors. They were scanned with X-rays generated by a sealed microfocus X-ray tube (tungsten anode) at $90 \mathrm{keV}$ and $110 \mu \mathrm{A}$ with an integration time of $400 \mathrm{~s}$. Samples were rotated over $360^{\circ}$ at rotation steps of $0.2^{\circ}$. A $3.0 \mathrm{~mm}$ thick aluminium filter was placed in front of the detector to remove low-energy X-rays.

\section{Data analysis}

The resulting two-dimensional images (16-bit TIF) were used to reconstruct the digital three-dimensional (3-D) object. Collected data were used to reconstruct a 3-D image with a resolution of $1024 \times 1024$ pixels and with an isotropic voxel size of $25 \mu \mathrm{m}$. 3-D software (TRI/3D-BON, Raroc System Engineering Company Limited, Tokyo, Japan) was used for visualization and analysis of the 3-D/volumetric data. The reconstructed data set was imported and displayed for 3-D visualization.

Visualization and data re-construction were performed using TRI/3D-BON (RATOC System Engineering, Tokyo, Japan). The volumes of the gaps and voids of the root canal and preparation size were calculated from the cementoenamel junction up to the apex after first and second root canal obturation.

\section{Statistical analysis}

Statistical analysis of the data was performed using the MannWhitney $U$-test and a value of $\mathrm{p}<0.05$ was considered significant.

\section{Results}

After first time obturation, 6 well-obturated artificial teeth were selected based on the 2-D-dental X-ray image (No.1 No.6). There were no gaps and voids in the root canal which could be seen with the naked eye. They were scanned by micro-CT. Figure 1 shows a 2-Ddental X-ray image and micro-CT image after obturation performed the first time and second time by the students (No.1 No.6).

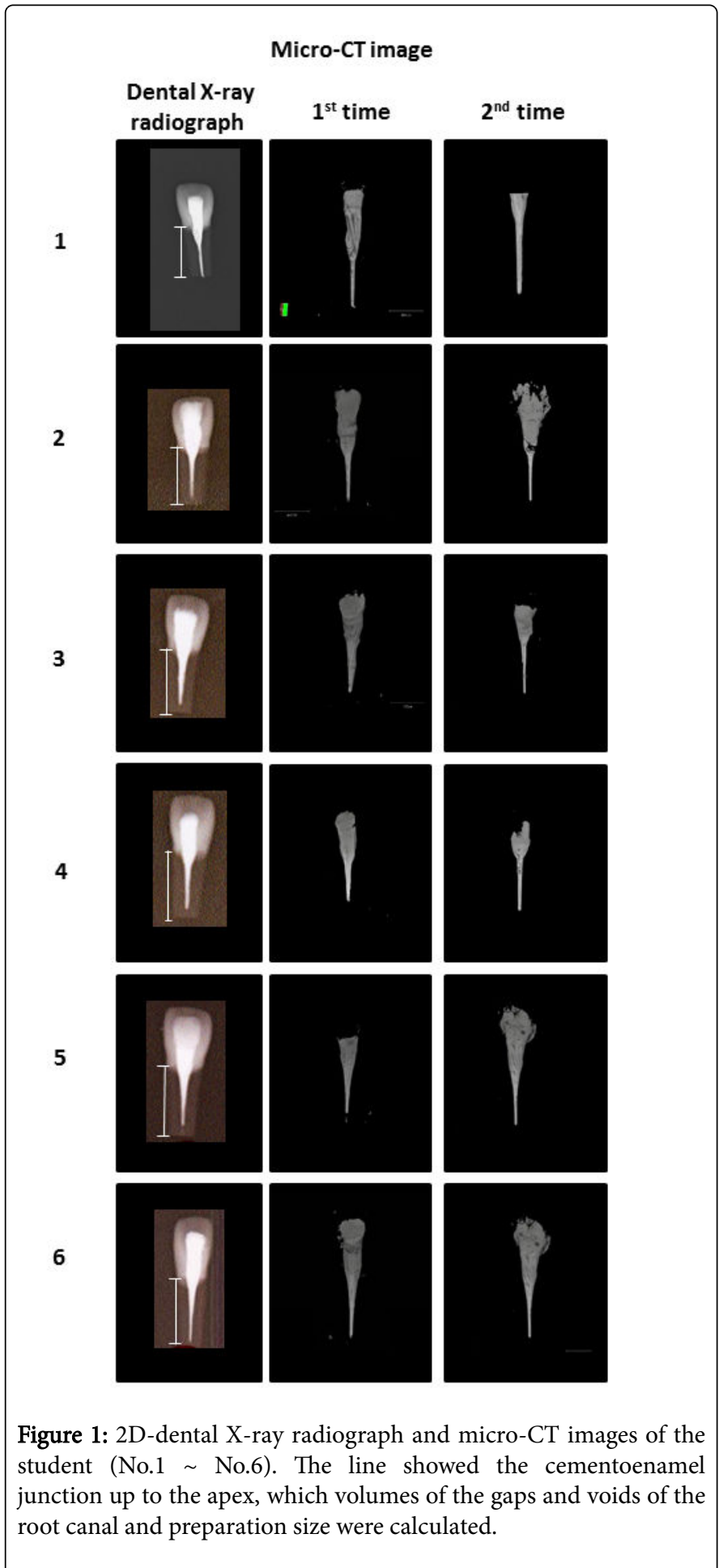


Among 6 artificial teeth, heavy bent gutta-percha points were observed in one root canal and moderate bent points were seen in two canals. No bent gutta-percha points were observed in three root canals. After second time obturation, the treated artificial root canals were scanned by micro-CT. Among 6 canals, moderate bent points were seen in 2 canals. No bent gutta-percha points were observed in 4 root canals (Figure 1).

The gaps and voids and the preparation size were calculated from the cementoenamel junction up to the apex. Each value of the student at the first time and second time are shown (Table 1). After first root canal obturation, the mean value of the gaps and voids was $0.8557 \pm$ $0.8005\left(\mathrm{~mm}^{3}\right)$ and after second root canal obturation, mean value of the gaps and voids was $0.1474 \pm 0.2579\left(\mathrm{~mm}^{3}\right)$ (Figure 2A). Significant differences was observed in the value of the gaps and voids between the first time and second time obturation groups ( $\mathrm{p}=0.05)$. After first root canal obturation, mean value of the preparation size was $6.9356 \pm$ $7.7321\left(\mathrm{~mm}^{3}\right)$ and after second root canal obturation, mean value was $8.7288 \pm 15.2110\left(\mathrm{~mm}^{3}\right)$ (Figure $2 \mathrm{~B}$ ). No significant changes in the preparation size were observed.

\begin{tabular}{|c|c|c|c|c|}
\hline \multirow{2}{*}{ Student No. } & \multicolumn{2}{|c|}{ Gaps and Voids } & \multicolumn{2}{c|}{ Expanding Root Canal Amount } \\
\cline { 2 - 5 } & First time & Second time & First time & 2.0813 \\
\hline 1 & 0.0757 & 0.0013 & 2.2083 & 1.4548 \\
\hline 2 & 0.0534 & 0.0120 & 2.1334 & 1.9880 \\
\hline 3 & 1.5600 & 0.6080 & 2.0560 & 1.7455 \\
\hline 4 & 0.2231 & 0.0255 & 2.9456 & 3.5926 \\
\hline 5 & 0.6055 & 0.0468 & 3.3244 & 2.5250 \\
\hline 6 & 1.8357 & 0.0448 & 5.7153 & $8.7288 \pm 15.2110$ \\
\hline Mean \pm SD & $0.8557 \pm 0.8005^{*}$ & $0.1474 \pm 0.2579^{*}$ & $6.9356 \pm 7.7321$ & \\
\hline * There were significant differences $(p=0.05)$ between first time and second time.
\end{tabular}

Table 1: The value of the gaps and voids and the expanding root canal amount.

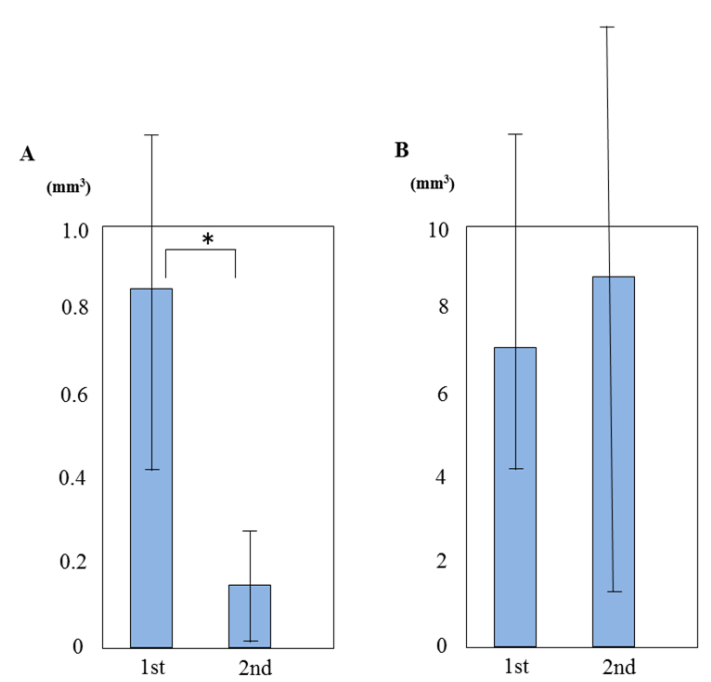

Figure 2: (A) Mean value of the gaps and voids after first time and second time root canal obturation $\left({ }^{*} p<0.05\right)$. (B) Mean value of the preparation size after first time and second time root canal obturation (No significant changes in the preparation size were observed).

\section{Discussion}

Micro-CT technology is currently being used to study dental anatomy, expand the knowledge of the endodontic instrumentation and irrigation methods [9-12] without destroying the sample. It enables analysis of volume changes, cross-sectional shape, taper, and proportion of prepared surface by matching reconstructed sample volumes of preoperative and postoperative canal systems $[6,13,14]$.

In this study, micro-CT was considered useful for the evaluation of endodontic treatment by inexperienced student and teaching materials. The endodontic treatment performed within the canal cannot be seen outside directly. Even when using the microscope, all figures of root canal enlargement and obturation were not seen in the monitor. Every dentist has the experience of performing endodontic treatment for the first time in the patients at the clinic. Also, all patients would like to receive proper endodontic treatment even if it is the first time. Educational practice is very important in the field of endodontics.

Nowadays, Japanese children are rarely seen playing outdoors in the park [15]. They prefer to play TV games inside the room, whereas high school students more often use smart phones instead of writing letters. They are not used to seeing the original 3-D view of objects. Therefore, we have to offer 3-D images for the students.

Micro-CT imaging combined together with rendering software allows the imaging and 3-D analysis of tooth structures [3,16-19]. High-resolution imaging provides a comprehensive analysis of the endodontic morphology and it gives additional information regarding the complex root canal system [17,20-23]. 
The students were expected to insert the gutta-percha points one by one without bending. However, outcomes showed that among the 6 artificial teeth, heavy bent gutta-percha points were observed in one root canal and moderate bent points were seen in 2 canals. No bent gutta-percha points were observed in 3 root canals. After the micro-CT images were shown to students, bent gutta-percha points were reduced. A better comprehension of the obturation was obtained. However, still bent gutta-percha points were observed. Micro-CT images revealed that there were gaps and voids. The gaps and voids had formed because the second and third gutta-percha points did not reach the bottom. Too much pressure caused the bending of the gutta-percha point, whereas weak pressure resulted in gaps and voids. The students must be trained to use an optimal pressure so as to avoid bending of the points [24].

When the micro-CT image was used, the gaps and voids were reduced. On the other hand, the preparation size showed no change. The micro-CT image helps to clearly visualize the outline as well as the preparation of the root canal.

The students' impressions of micro-CT image were mostly favorable. They evaluated the root canal fillings based on dental X-ray images. However, the micro-CT image revealed that there were gaps, voids and bent points in the canal. Students can clearly understand the complexities of root canal treatment and fillings through the micro-CT image. They mentioned that they could not understand the outcome of the root canal filling based on only dental X-ray images. Recently, Keleş et al. reported evaluation of removal of the filling materials from root canals with micro-computed tomography. Micro-CT image was useful for the evaluation of retreatment procedure [25].

\section{Conclusion}

These results suggested that micro-CT was useful for the evaluation of teaching materials and outcomes of endodontic treatment performed by inexperienced students. Micro-CT might also be useful for further endodontic training in procedures like $\mathrm{Ni}$-Ti file root canal preparation, vertical condensation and retreatment procedures.

\section{References}

1. Shen Y, Cheung GSP (2013) Methods and models to study nickeltitanium instruments. Endod Topics 29: 18-41.

2. Pasqualini D, Bianchi CC, Paolino DS, Mancini L, Cemenasco A, et al. (2012) Computed micro-tomographic evaluation of glide path with nickel-titanium rotary PathFile in maxillary first molars curved canals. J Endod 38: 389-393.

3. Paque F, Ganahl D, Peters OA (2009) Effects of root canal preparation on apical geometry assessed by micro-computed tomography. J Endod 35: 1056-1059.

4. Nair MK, Nair UP (2007) Digital and advanced imaging in endodontics: a review. J Endod 33: 1-6.

5. Balto K, Muller R, Carrington DC, Dobeck J, Stashenko P (2000) Quantification of periapical bone destruction in mice by micro-computed tomography. J Dent Res 79: 35-40.

6. Pasqualini D, Alovisi M, Cemenasco A, Mancini L, Paolino DS, et al. (2015) Micro-computed tomography evaluation of ProTaper Next and BioRace shaping outcomes in maxillary first molar curved canals. J Endod 41: 1706-1710.
7. Marceliano-Alves M, Alves FR, Mendes Dde M, Provenzano JC (2016) Micro-computed tomography analysis of the root canal morphology of palatal roots of maxillary first molars. J Endod 42: 280-283.

8. Selem LC, Li G, Niu L, Bergeron BE, Bortoluzzi EA, et al. (2014) Quality of obturation achieved by a non-gutta-percha-based root filling system in single-rooted canals. J Endod 40: 2003-2008.

9. Peters OA, Schönenberger K, Laib A (2001) Effects of four Ni:Ti preparation techniques on root canal geometry assessed by micro computed tomography. Int Endod J 34: 221-230.

10. Paqué F, Boessler C, Zehnder M (2011) Accumulated hard tissue debris levels in mesial roots of mandibular molars after sequential irrigation steps. Int Endod J 44: 148-153.

11. Freire LG, Iglecias EF, Cunba RS, Santos M, Gavini G (2015) Microcomputed tomographic evaluation of hard tissue debris removal after different irrigation methods and its influence on the filling of curved canals. J Endod 41: 1660-1666.

12. Gao Y, Fan B, Cheung GS, Gutman JL, Fan M (2006) C-shaped canal system in mandibular second molars part IV: 3-D morphological analysis and transverse measurement. J Endod 32: 1062-1065.

13. Peters OA, Laib A, Gohring TN, Barbakow F (2001) Changes in root canal geometry after preparation assessed by high-resolution computed tomography. J Endod 27: 1-6.

14. Moore J, Fitz-Walter P, Parashos P (2009) A micro-computed tomographic evaluation of apical root canal preparation using three instrumentation techniques. Int Endod J 42: 1057-1064.

15. Kashikura H (2007) Children of today and play (2)-From comparison with play in the Showa period. Bull of Uyo Gakuen College 8: 123-133.

16. Domark JD, Hatton JF, Benison RP, Hildebolt CF (2013) An ex vivo comparison of digital radiography and cone-beam and micro computed tomography in the detection of the number of canals in the mesiobuccal roots of maxillary molars. J Endod 39: 901-905.

17. Plotino G, Grande NM, Pecci R, Bedini R, Pameijer CH (2006) Threedimensional imaging using microcomputed tomography for studying tooth macromorphology. J Am Dent Assoc 137: 1555-1561.

18. Peters OA, Boessler C, Paqué F (2010) Root canal preparation with a novel nickel-titanium instrument evaluated with micro-computed tomography: canal surface preparation over time. J Endod 36: 1068-1072.

19. Peters OA, Paqué F (2011) Root canal preparation of maxillary molars with the self-adjusting file: a micro-computed tomography study. J Endod 37: 53-57.

20. Ahmad AA, AI-Jadaa A (2014) Three root canals in the mesiobuccal root of maxillary molars: case reports and literature review. J Endod 40: 2087-2094.

21. Park JW, Lee JK, Ha BH, Choi JH, Perinpanayagam H (2009) Threedimensional analysis of maxillary first molar mesiobuccal root canal configuration and curvature using micro-computed tomography. Oral Surg Oral Med Oral Pathol Oral Radiol Endod 108: 437-442.

22. Somma F, Leoni D, Plotino G, Grande NM, Plasschaert A (2009) Root canal morphology of the mesiobuccal root of maxillary first molars: a micro-computed tomographic analysis. Int Endod J 42: 165-174.

23. Verma P, Love RM (2011) A micro CT study of the mesiobuccal root canal morphology of the maxillary first molar tooth. Int Endod J 44: 210-217.

24. Briseño-Marroquín B, Paqué F, Maier K, Willershausen B, Wolf TG (2015) Root canal morphology and configuration of 179 maxillary first molars by means of micro-computed tomography: An ex vivo study. J Endod 41: 2008-2013.

25. Keleș A, Arslan H, Kamalak A, Akçay M, Sousa-Neto MD, et al. (2015) Removal of filling materials from oval-shaped canals using laser irradiation: a micro-computed tomographic study. J Endod 41: 219-224. 